\title{
Characterization of triglycine sulfate (TGS) crystals grown in water-soluble CdS nanoparticles dispersed in water
}

\author{
K. Balasubramanian ${ }^{1}$, P. Selvarajan ${ }^{2 *}$ and E. Kumar ${ }^{3}$ \\ ${ }^{1}$ Department of Physics, The MDT Hindu College, Tirunelveli-627010, Tamilnadu, India \\ ${ }^{2}$ Department of Physics, Aditanar College of Arts and Science, Tiruchendur-628216, Tamilnadu, India \\ ${ }^{3}$ PRIST University, Thanjavur, Tamilnadu, India \\ pselvarajanphy@yahoo.co.in*
}

\begin{abstract}
Single crystals of Triglycine Sulfate (TGS) were grown in water and also were grown in water-soluble CdS nanoparticles dispersed in water by solution method with slow evaporation technique at room temperature. Watersoluble CdS nanoparticles were synthesized by microwave-assisted solution method using the precursors such as cadmium sulfate, thioglycolic acid and ethylene diamine and they were used for the growth of CdS-added TGS crystals. The grown crystals were characterized by XRD technique, UV-visible spectral studies, measurement of density, microhardness studies, atomic absorptions studies. The effect of $\mathrm{Cd}^{2+}$ ions on various properties of TGS crystals have been analyszed and reported.
\end{abstract}

Keywords: Crystal growth, XRD, TGS crystals, CdS nanoparticles.

\section{Introduction}

Triglycine sulfate (TGS) crystal is one of the interesting ferroelectric materials which finds applications in the fabrication of infrared detectors, pyroelectric vidicon tubes operating at room temperature, in the fabrication of capacitors, transducers and sensors (Ashok $\mathrm{K}$ Batra et al., 2003; Berbacaru et al., 2005). It has a second-order phase transition at the Curie point $\left(49^{\circ} \mathrm{C}\right)$. The crystal is monoclinic in structure below and above the Curie temperature. The space group transforms from $P 2_{1}$ in the ferroelectric phase to centro-symmetric space group $\mathrm{P}_{2} / \mathrm{m}$ in the paraelectric phase. In TGS, ferroelectric property is observed only along $b$-axis and it has high pyroelectric coefficient and low dielectric constant. Below Curie point, TGS crystal possesses antiparallel $180^{\circ}$ domains, which are generally parallel to b-axis. The domains in a TGS crystal are rod shaped with lenticular cross-sections elongated in the direction perpendicular to the crystallographic c-axis (Fang et al., 1995; Selvarajan et al., 1993).

Undoped TGS crystals have some disadvantages over doped TGS crystals such as the ferroelctric domains possess high mobility at room temperature, easy depolarization by electrical and thermal means, microbial contamination with time during the growth and low Curie point. These disadvantages can be overcome by adding suitable impurities to the lattice sites of TGS crystals (Sun et al., 1999; Raghavan et al., 2008; Selvarajan et al., 2008). So far, the semiconductor material like cadmium sulphide (CdS) has not been introduced into the lattice of TGS crystal in order to alter its physical and chemical properties. To add CdS impurity in the lattice of TGS, we use water-soluble CdS nanoparticles dispersed in water as the growth medium. Preparation of water-soluble CdS nanoparticles reported elsewhere (Barglik-Chory et al., 2003). Water-soluble nanoparticles have peculiar properties such as dispersability and solubility in aqueous medium, nanometer size and narrow-size distribution. In this work, we report the results of growth by solution method and others such as single crystal and powder XRD studies, UV-visible transmittance studies, microhardness studies, atomic absorption studies, measurement of density of the grown crystals.

Experimental methods

Synthesis of TGS salt and water-soluble CdS nanoparticles

TGS salt was synthesized by taking Analar Grade (AR) glycine $\left(\mathrm{NH}_{2} \mathrm{CH}_{2} \mathrm{COOH}\right)$ and concentrated sulphuric acid $\left(\mathrm{H}_{2} \mathrm{SO}_{4}\right)$ in the ratio $3: 1$. The required volume of concentrated sulphuric acid was diluted with de-ionized water. Then the calculated amount of glycine salt was dissolved in the diluted sulphuric acid to prepare solution and it was heated at $50{ }^{\circ} \mathrm{C}$ to obtain the synthesized salt of TGS.

Water-soluble CdS nanoparticles were prepared using Analar Grade (AR) reagents of cadmium sulfate and thioglycolic acid. These precursors were taken in 1:1 molar ratio and dissolved in de-ionized water. The solution was stirred well for about 2 hours using a magnetic stirrer. Then it was kept in a domestic microwave oven (900 W, $2450 \mathrm{MHz}$, Onida, India) for about 30 minutes at $70^{\circ} \mathrm{C}$ to obtain water-soluble $\mathrm{CdS}$ nanoparticles. When nanoparticles were formed during the reaction between cadmium sulfate and thioglycolic acid, ethylene diamine was added to the solution. The obtained nanoparticles were filtered and dried at $40^{\circ} \mathrm{C}$.
Research article

CIndian Society for Education and Environment (iSee)
"Crystal growth"

http://www.indjst.org
Balasubramanian et al. Indian J.Sci.Technol. 


\section{Growth of pure and CdS-doped TGS crystals}

Growth of TGS grown in water and also grown in CdS nanoparticles dispersable in water was carried out by solution method with slow evaporation technique at room temperature $\left(30^{\circ} \mathrm{C}\right)$. The synthesized salt of TGS was dissolved in de-ionized water to prepare the mother solution and it was constantly stirred for about 2 hours using a magnetic stirrer and it was filtered using 4 micro Whatmann filter paper. Then the filtered solution was kept in a Borosil beaker covered with porous paper for slow evaporation. To grow TGS crystals in water-soluble CdS nanoparticles dispersed in water, $1 \mathrm{~mol} \%$ of CdS nanoparticles were added to solvent. The growth period allowed to harvest sample crystals was about 35 days. The grown crystals are displayed in the Fig. 1 and it is observed that TGS crystals grown in CdS nanoparticles dispersed in water are slightly yellow in colour which indicates the incorporation of CdS into the lattice of TGS crystals. In the lattice of TGS, CdS may be in the form of ions or molecules. The crystals' shape and size are sensitive to the amount of CdS in the solution during the growth. During the growth, adsorption of dopants on the crystal surface takes place and hence the dopants have been introduced into the lattice of the TGS crystals.

\section{Characterization techniques}

The grown single crystals were subjected to single crystal X-ray Diffraction (XRD) study using an ENRAF NONIUS CAD4 diffractometer with $\mathrm{MoK}_{\alpha}$ radiation $\left(\lambda=0.71073 A^{\circ}\right)$ to find the cell dimensions, space group and number of molecules per unit cell. The powder XRD study was carried out by employing a powder X-ray diffractometer (PANalytical Model, Nickel filtered $\mathrm{Cu} \mathrm{K}$ radiations $(\lambda=1.54056 \AA)$. The samples were scanned over the $2 \Theta$ range of $10-70^{\circ}$ at a rate of $1^{\circ} \mathrm{min}^{-1}$. Atomic absorption studies were carried out using an atomic absorption spectrometer (Model: AA 6300) to confirm the presence of cadmium in the lattice of CdSdoped TGS crystal. A Varian Cary 5E UV-Visible-NIR spectrophotometer was used for spectral transmission studies. A crystal thickness of about $2 \mathrm{~mm}$ was used for transmission studies. The floatation method was employed for the precise determination of density. Microhardness studies of the grown crystals were carried out using Leitz Weitzler hardness tester fitted with a diamond indenter. Smooth, flat surface was selected and subjected to this study on the (010) plane of both samples.. Indentations were made for various loads from $10 \mathrm{~g}$ to $25 \mathrm{~g}$. The Vickers microhardness number was calculated using the relation $\mathrm{H}_{\mathrm{v}}=1.8544 \mathrm{P} / \mathrm{d}^{2} \mathrm{~kg} / \mathrm{mm}^{2}$, where $P$ is the applied load and $d$ is the diagonal length of the indentation impression.

\section{Results and discussions}

The grown crystals were subjected to single crystal XRD studies and the obtained lattice parameters are $a=$ 9.293(2) $\AA, b=12.713(1) \AA \hat{,} c=5.732(2) \AA \hat{,}, \alpha=90^{\circ}, \beta=$ $110.45(2), \gamma=90^{\circ}$ and $a=9.349(3) \AA \dot{A}, b=12.704(2) \AA$,
Vol. 3 No. 1 (Jan 2010)

ISSN: 0974- 6846

$\mathrm{C}=5.758(2) \AA \hat{A}, \quad \alpha=90^{\circ}, \beta=109.34$ (3), $\gamma=90^{\circ}$ respectively for TGS single crystals grown in water and grown in CdS nanoparticles dispersed in water. The obtained cell parameters of TGS crystal were found to be well matched with the reported values (Muralidharan et al., 2002). Single crystal XRD studies show that both the samples crystallize in monoclinic structure with the space group $\mathrm{P} 2{ }_{1}$.

Table 1. Values of Vickers for the samples with various loads

\begin{tabular}{|c|c|c|}
\hline \multicolumn{3}{|c|}{ loads } \\
& $\begin{array}{c}\mathrm{H}_{\mathrm{v}} \\
\left(\mathrm{kg} / \mathrm{mm}^{2}\right) \\
\text { for TGS } \\
\text { crystal } \\
\text { (water) }\end{array}$ & $\begin{array}{c}\mathrm{H}_{\mathrm{v}} \\
\left(\mathrm{kg} / \mathrm{mm}^{2}\right) \\
\text { for TGS } \\
\text { crystal } \\
(\mathrm{CdS})\end{array}$ \\
\hline $10 \mathrm{~g}$ & 233 & 241 \\
\hline $15 \mathrm{~g}$ & 236 & 245 \\
\hline $20 \mathrm{~g}$ & 240 & 249 \\
\hline $25 \mathrm{~g}$ & 245 & 256 \\
\hline
\end{tabular}
microhardness $\left(H_{v}\right)$ number

The number of molecules per unit cell was found to be 2 for both the crystals. It is observed from the results that there is slight change of cell parameter values when $\mathrm{CdS}$ is incorporated into the lattice of TGS crystals. The powder X-ray diffraction (XRD) patterns of pure and CdS- doped TGS crystals are shown in Fig.2. The well-defined peaks at specific 2-theta values show high crystallinity of the grown crystals. All the reflections of powder XRD patterns of this work were indexed using the TREOR software package. Also UNITCELL software package was used to confirm the indexing. It is to be mentioned here that powder XRD studies were performed on the pure and CdS-added TGS crystals to check the correctness of the values of unit cell parameters obtained from single crystal XRD studies and to find diffracting planes of the crystals.

\section{Fig. 1. Grown crystals of undoped and CdS-doped TGS}

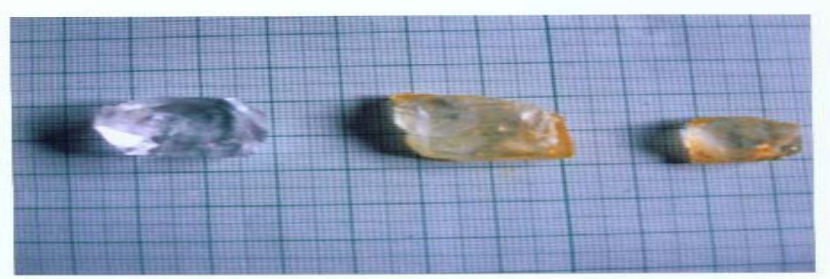

The recorded transmittance spectra of the sample crystals in the wavelength range $200-1100 \mathrm{~nm}$ are shown in Fig.3. From the transmittance spectra, it is noticed that TGS crystal grown in water has a transmittance of more than $95 \%$ in the visible region. A strong absorption is observed at $230 \mathrm{~nm}$ for the grown crystals and this corresponds to the fundamental absorption and UV cutoff wavelength. Absorption in the near ultraviolet region arises from electronic transitions associated within the samples. The observed behaviour of the spectra and band gap value found in this work are in good agreement with UV-visible spectral data of TGS crystal reported in the literature (Balamurugan et al., 2007). From the results, it is observed that the transmittance for the TGS crystal grown in water-soluble CdS nanoparticles dispersed in water decreases and hence the absorbance increases. From the Fig.3, it is noticed that there is an 
absorbance in the range $490-520 \mathrm{~nm}$ and it may be due slight yellowish colour CdS-added TGS crystals.

The density of pure and CdS-added TGS crystals was found to be $1.676 \mathrm{~g} / \mathrm{cc}$ and $1.724 \mathrm{~g} / \mathrm{cc}$ respectively. The change of density indicates the incorporation of impurity in TGS crystal. If the dopant occupies the crystal lattice, mass increases and hence density increases. The presence of cadmium in the CdS-doped TGS crystal was confirmed by atomic absorption spectroscopic (AAS) study and the concentration of the cadmium was found to be $984 \mathrm{ppm}$. Table 1 shows the values of Vickers microhardness number for pure and CdS-added TGS crystals with the various loads. In an ideal crystal, the hardness value should be independent of applied load. But in a real crystal, the load dependence is observed and this is due to normal indentation size effect (ISE). In this work, the hardness increases slightly with increase in the load for the grown crystals of this work. For CdSadded TGS crystal, hardness is more than that of pure TGS crystal at all loads up to $25 \mathrm{~g}$. For loads above 25 $\mathrm{g}$, cracks started developing around the indentation mark. It is due to the release of internal stress generated locally by indentation (Theresita Shanthi et al., 2009).

Fig.2. Powder XRD patterns of (a) undoped

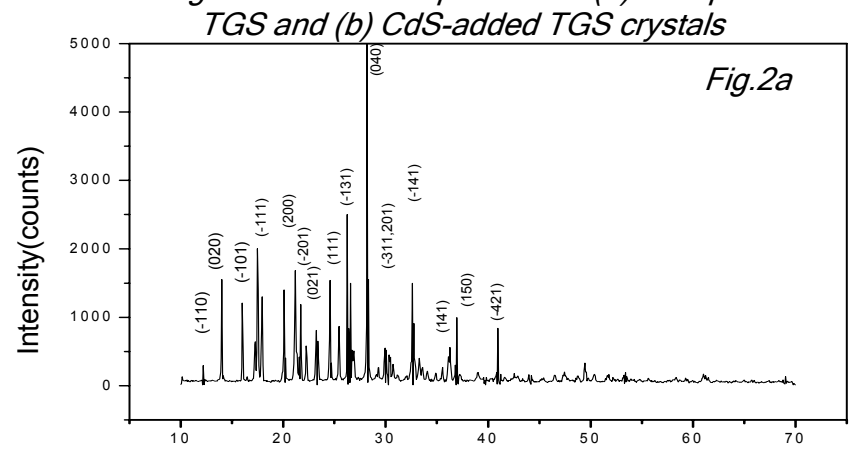

2 theta(degrees)

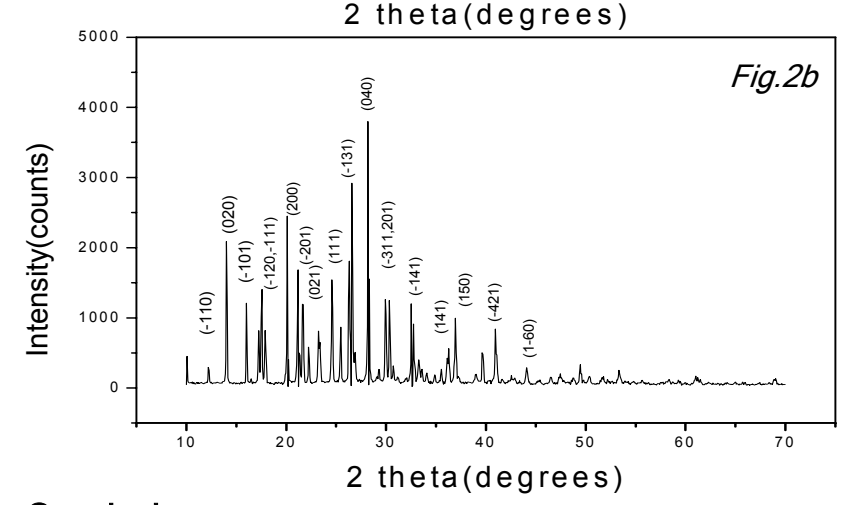

\section{Conclusions}

Water-soluble CdS nanoparticles were prepared by microwave-assisted solution method. CdS-added TGS crystals were grown in water-soluble CdS nanoparticles dispersed in water. The dopants may be in the form of ions or CdS molecules. Single crystal and powder XRD studies reveal the monoclinic structure of the grown crystals. The presence of cadmium in the doped-TGS crystals is confirmed by atomic absorption studies. The values of density and microhardness number are found to be increased when TGS crystals are doped with cadmium sulphide. An absorption band is observed in the range 490-520 $\mathrm{nm}$ in the UV-visible transmittance spectrum which indicates the presence of impurity (CdS) in the lattice of cadmium sulphide-added TGS crystals.

\section{Acknowledgement}

P.S. is grateful to Aditanar Educational Institutions for providing enough funds to develop crystal growth centre.

\section{References}

1. Ashok K. Batra, Mohan D. Aggarwal and Ravindra B. Lal (2003) Growth and characterization of doped DTGS crystals for infrared sensing devices. Materials Lett. 57, 3943-3948.

2. Balamurugan $\mathrm{N}$, Lenin $\mathrm{M}$, Bhagavannarayana G, Ramasamy P (2007) Growth of TGS crystals using uniaxially solution-crystallization method of Sankaranarayanan-Ramasamy. Crystal Res. Technol. 42, 151-156.

3. Barglik-Chory Ch., Buchold D, Schmitt M, Kiefer W, Heske C, Kumpf C, Fuchs O, Weinhardt L, Stahl A, Umbach E, Lentze M, Geurts J and Muller G (2003) Synthesis, structure and spectroscopic characterization of water-soluble CdS nanoparticles. Chemical Physics Lett. 379, 443-451.

4. Berbacaru C, Alexandru HV, Pintilie L, Dutu A, Logofatu B and Radulescu RC (2005) Doped versus pure TGS crystals. Materials Sci. Engg. B11, 141-146.

5. Fang CS, Liu H, Zhuo HS, Wang M and Xu D (1995) A new modified TGS crystal. Cryst. Res. Technol. 30, 785-789.

6. Muralidharan R, Mohankumar R, Ushasree PM, Jayavel R and Ramasamy P (2002) Effect of rare-earth dopants on the growth and properties of triglycine sulphate crystals. $J$. Crystal Growth. 234, 545-550.

7. Raghavan CM, Sankar R, Mohan Kumar R, Jayavel $R$ (2008) Effect of amino acid doping on the growth and ferroelectric properties of triglycine sulphate single crystals. Materials Res. Bull. 43, 305-311.

8. Selvarajan $P$, Siva dhas ATH, Freeda TH and Mahadevan CK (2008) Growth, XRD and dielectric properties of triglycine sulpho-phosphate (TGSP) crystals added with magnesium sulfate. Physica B. 403, 4205-4208.

9. Selvarajan P, Das BN, Gon HB and Rao KV (1992) Dielectric properties of quenched and $X$ - ray irradiated triglycine sulphate single crystals later excited with laser light. J. Mat. Sci. Lett. 11, 1312-1314.

10. Sun X, Wang M, Pan QW, Shi W and Fang CS (1999) Study
Fig. 3. UV-Visible transmittance spectra of undoped and CdS-added TGS crystals

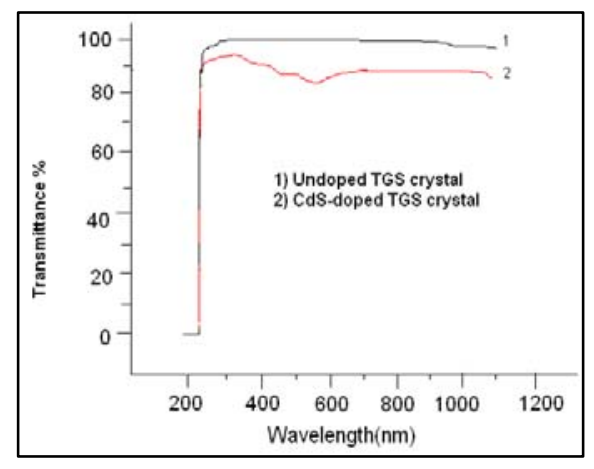
on the growth and properties of quanidine doped triglycine sulfate crystal. Cryst. Res. Technol. 34, 12511254.

11. Theresita Shanthi, Selvarajan $\mathrm{P}$ and Mahadevan CK (2009) Studies on triglycine sulfate (TGS) crystals doped with sodium bromide ( $\mathrm{NaBr})$ grown by solution method. Indian J. Sci. Technol. 2(3), 49-52..

Balasubramanian et al. Indian J.Sci.Technol.
"Crystal growth"

http://www.indjst.org
Research article

Clndian Society for Education and Environment (iSee) 